Please note that this is the pre-publication version of an article currently in press at

The International Journal for the Psychology of Religion

\title{
Prodigal sons: Dual Abrahamic categorization mediates the detrimental effects of religious fundamentalism on Christian-Muslim relations
}

The correct citation for this article is:

Kunst, J. R., \& Thomsen, L. (2014). Prodigal sons: Dual Abrahamic categorization mediates the detrimental effects of religious fundamentalism on Christian-Muslim relations. The International Journal for the Psychology of Religion. doi:

10.1080/10508619.2014.937965 


\title{
Prodigal sons: Dual Abrahamic categorization mediates the detrimental effects of religious fundamentalism on Christian-Muslim relations
}

Jonas R. Kunst ${ }^{1} \&$ Lotte Thomsen $^{123}$

1. Department of Psychology, University of Oslo, Pb 1094 Blindern, 0317 Oslo, Norway

2. Department of Psychology, University of Copenhagen, Øster Farimagsgade 2A, 1353 Copenhagen, Denmark

3.Department of Psychology, Harvard University, William James Hall, 33 Kirkland Street, Cambridge, MA 02138, USA

\begin{abstract}
Religious fundamentalism is associated with Christian-Islamic conflicts globally, but the psychological reasons remain unexplored. Here, we show that fundamentalism is detrimental to inter-religious relations because it makes Christians and Muslims alike reject common theological grounds and Abrahamic origins. Specifically, Study 1 demonstrated that such dual Abrahamic categories mediated the negative effects of fundamentalism on real monetary donations to out-group children desperately in need (i.e., Save the Children Syria) among Christians, but not Atheists. Importantly, this was the case only to the degree that Syrian children were perceived as Muslims and, hence, part of an Abrahamic out-group. Using a double-randomized experimental design, Study 2 demonstrated the causal effects of religious fundamentalism on Abrahamic categorization and of Abrahamic categorization on mutual resource distribution bias among Muslims and Christians. Together, these studies suggest that religious fundamentalism fuels inter-religious conflicts because it crucially impacts basic categorization processes, with subsequent negative effects on intergroup relations.
\end{abstract}

Key words: religious fundamentalism; common group; dual identity; Islam; Christianity; intergroup relations 
Religious fundamentalism regularly surfaces in public discourse on conflicts of both inter- and intranational scale, such as wars on terror, conflicts in the Middle East, or tense intergroup relations in multicultural societies. Although religious fundamentalism is often portrayed as confined to Muslims and the Islamic world, it can be found in virtually any religion (Altemeyer \& Hunsberger, 1992). Irrespective of their specific religious denomination, fundamentalists differ from their moderate religious peers in holding particularly preclusive religious conceptions, believing is a single right way to salvation that has to be followed rigidly (Altemeyer, 2003). Possibly to defend their stolid ideological stance (Brandt \& Reyna, 2010), individuals high on religious fundamentalism tend to hold negative attitudes towards dissentients (Hall, Matz, $\&$ Wood, 2010). Indeed, fundamentalist notions have repeatedly been used to justify extreme acts of violence towards other groups (Emerson \& Hartman, 2006), including the $12^{\text {th }}$-century crusades, atrocities as between Christians and Muslims in Nigeria, or terroristic mass murder, most recently as conducted by Christian fundamentalist Anders Behring Breivik.

Here, we propose that religious fundamentalism is particularly derogative for Christian-Islamic relations because it leads Muslims and Christians to overlook blatant theological commonalities between their religions, reinforcing the division between "us" and "them" that has detrimental effects on intergroup relations, as demonstrated by decades of work within the social identity tradition (Tajfel, 1982; Tajfel \& Turner, 1979). Yet, although often ignored in public discourse and religious education (Plante, 2009), Islam and Christianity are theologically related in many ways. Not only do various religious figures, such as Moses, Jesus, Noah or Jonah play important roles in both religions, but Islam and Christianity also both trace their origins to the progenitor Abraham/Ibrahim. Some contemporary religious leaders do recognize this common heritage. For instance, King Hussain of Jordan, arguably a descendent of the Prophet Mohammed, emphasized the importance to "bring together the Children of Abraham" (King Hussein I, 1991), while Pope John Paul II depicted Abraham as the "common forefather" in Lisbon in 1982.

Because such dual categories - notions of a shared, superordinate group including the in-group and immediate out-groups in addition to one's own subgroup category - generally attenuate intergroup bias (see, e.g., Dovidio, 
Gaertner, Shnabel, Saguy, \& Johnson, 2009; Gaertner \& Dovidio, 2000;

Gaertner \& Dovidio, 2005), here we test if endorsing a common Abrahamic group attenuates mutual intergroup bias among Muslims and Christians. Crucially, we predict that religious fundamentalism will limit the degree to which believers endorse such a dual Abrahamic religious category in the first place, precisely because fundamentalism involves a narrow worldview (Hunsberger \& Jackson, 2005) and a tendency to reject alternative religious interpretations (Brandt \& Reyna, 2010). This, we propose, is an underlying, mediating process that makes religious fundamentalism fuel hostile group relations in many parts of the world.

In a cross-national context, Study 1 tests whether endorsing the common origins of Christianity and Islam mediates the detrimental effects of religious fundamentalism on costly, altruistic helping of out-group children in dire need. To do so, we gave American workers on Amazon Mechanical Turk an unexpected bonus of $\$ 1$ and the opportunity to donate any or none of this amount to Save the Children Syria. In terms of limiting factors, we expected dual Abrahamic categorization to mediate the effect of religious fundamentalism on aid donations 1) only among Christians because it should be irrelevant for Atheists' self-concepts and 2) only to the degree that Syrians are perceived as Muslim, and hence as part of the Abrahamic group.

In a tense intra-national context, Study 2 tests the full causal chain of our proposed meditational model among Muslims and Christians in Germany using a double-randomized approach (see MacKinnon, Fairchild, \& Fritz, 2007; Sherman \& Gorkin, 1980). Specifically we test 1) if manipulating the saliency of religious fundamentalism causes dual Abrahamic categorization to change and 2) if manipulating dual Abrahamic categorization causes reduced mutual bias in Tajfel-like resource distribution scenarios, and leads to more positive feelings towards Abrahamic, but not non-Abrahamic, out-groups.

\section{Study 1}

\section{Material and Methods}

Participants. As no comparable studies were available to gather information about the expectable effect size, we conducted power analyses for a small effect $\left(f^{2}=.10\right)$ in regression-based analyses. Results indicated that $n=124$ 
would be needed to have at least an $80 \%$ chance to observe such an effect with a significance criterion of .05. This sample size would also meet the criteria of 100 to 150 participants suggested by Wang and Wang (2012) and a rule of thumb ratio of 10-20 participants per variable (see Tanaka, 1987). Although no information is available about the religious affiliation of workers on Amazon Mechanical Turk, we, based on census data, expected most MTurkers to identify as Christians, followed by Atheists and followers of other faiths. In order to ensure that we would meet the minimum sample for both Christians and Atheists, we collected data from all in all 400 participants through Amazon Mechanical Turk. Of these participants, 179 were Christians, 134 Atheists and 87 identified with other religious affiliations. Due to the purpose of our study, only Christian and Atheist participants were retained for analyses $\left(M_{\text {age }}=34.36, S D_{\text {age }}=11.82\right.$; males $=60.4 \%)$.

Procedure and Measures. Respondents were paid 70 cents for participating in a study on "social issues". They first answered questions assessing religious fundamentalism as well as strength of religious identification in randomized order, as subgroup identification has been found to negatively predict common categorizations (Gaertner \& Dovidio, 2000) so that religious identification is an important control variable. Next, participants answered a measure assessing dual Abrahamic categorization and were then given the opportunity to donate all or none of a surprise $\$ 1$ bonus to Save the Children Syria before answering demographic questions ${ }^{1}$. Unless stated otherwise, all responses were scored on 7-point Likert scales with 1 (totally disagree) and 7 (totally agree) as endpoints. All analyses were run with SPSS 21 and the PROCESS regression macros (Hayes, 2013).

Religious fundamentalism. The revised religious fundamentalism scale (Altemeyer \& Hunsberger, 2004) was used to measure fundamentalist beliefs ( $\alpha$ $=.97)$. The scale consists of 12 items, such as "To lead the best, most meaningful life, one must belong to the one, fundamentally true religion" or "God has given humanity a complete, unfailing guide to happiness and salvation, which must be totally followed." 
Religious identification. We used an adapted version of the collective self-esteem scale (Luhtanen \& Crocker, 1992) to measure religious identification $(\alpha=.94)$. Participants indicated their agreement with four items such as "The religion I belong to is an important reflection of who I am."

Dual Abrahamic categorization. We wrote four items to reflect the dual identity conceptionalization of Dovidio, Gaertner, and Saguy (2007). Specifically, participants indicated their agreement with the statements "Because Abraham is the progenitor of both Islam and Christianity, one can say that Muslims and Christians belong to the same "family' of religions", "Christians as well as Muslims believe in an Abrahamic religion", "Christianity and Islam have common roots" and "Even though Islam and Christianity are different religions, both belong to the same group of religions", forming a reliable scale $(\alpha=.93)$.

Donation task. Participants read information about the conflict in Syria adapted from the Save the Children Syria webpage. Next, they were told that they had received a payment bonus of $\$ 1$ and asked if they would like to donate any given amount between 0 and 100 cents (using a sliding response scale):

"4 million Syrian children are suffering as a result of a horrific conflict one of the worst humanitarian crises of our time - which is now stretching into its third year. Two million people have fled to neighboring countries Iraq, Lebanon and Jordan, but many more remain in dire need of assistance. Save the Children Syria is on the ground helping to keep children safe, providing the basics they need, like food and blankets and offering programs to help them cope with tragedy. We grant you a 1 dollar bonus for your participation in our study. How much of this bonus would you like to donate to Save the Children Syria?"

At the very end of the study, after answering demographic questions, we asked participants to indicate the percentage of the Syrian population they believed to be Muslim: "How many percent of the Syrian population do you think is Muslim? (Please do not use the internet to find the right answer, we are only interested in your own, rough estimate.)" This was done to assess the degree to which participants indeed perceived Syrians as a Muslim, hence Abrahamic, out-group. 


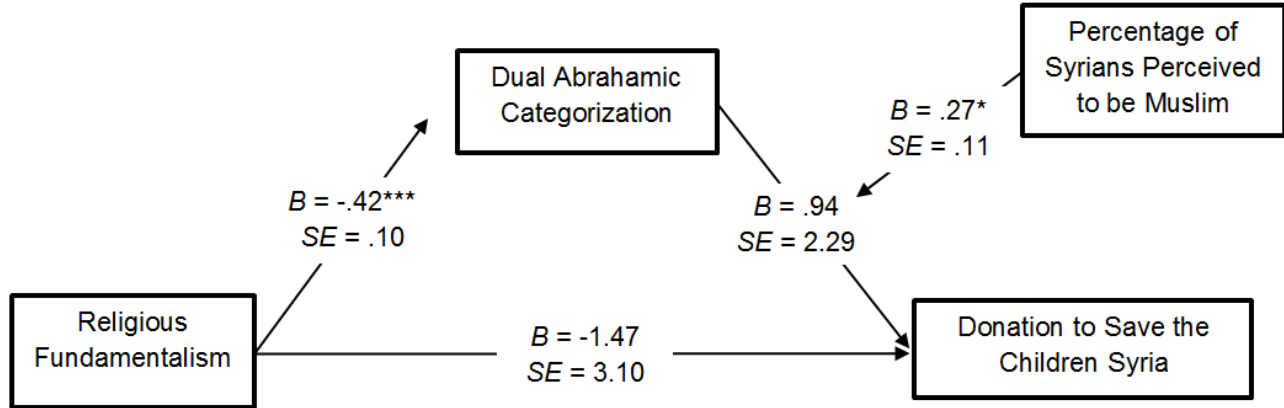

Figure 1. Estimated second-stage moderated mediation model in Study 1 is displayed. Religious identification is controlled for. ${ }^{*} p<.05,{ }^{* * *} p<.001$.

\section{Results}

While participants in total donated $116.69 \$$ out of $398 \$$ to Save the Children Syria, Christians donated significantly more $(M=34.62$ cents, $S D=$ 39.44) than Atheists $(M=20.73$ cents, $S D=30.79 ; t(310.43)=-3.49, p=.001$, $\left.\eta^{2}=.04\right)$. Also, the donation variable was positively skewed only among Atheists (skewness $=1.49$ ) but not among Christians ( bkewness $=0.69$ ).

We conducted second-stage moderated mediation analyses (Edwards \& Lambert, 2007), with religious fundamentalism as predictor variable, dual Abrahamic categorization as mediator, donation as dependent variable and percentage of Syrians perceived to be Muslim as moderator of the relation between dual Abrahamic categorization and donation (see Figure 1). As the distinction between Christians and Atheists is central to the hypotheses of the study, the analyses were run separately for both groups. Religious identification, which was positively related to religious fundamentalism $(r=.80, p<.001)$, negatively related to dual Abrahamic categorization $(r=-.34, p<.001)$ and was unrelated to the remaining variables $(.574<p s<.581)$, was controlled for as covariate in each stage of the analyses.

Table 1

Dual Abrahamic Categorization Regressed on Religious Fundamentalism and Religious Identification

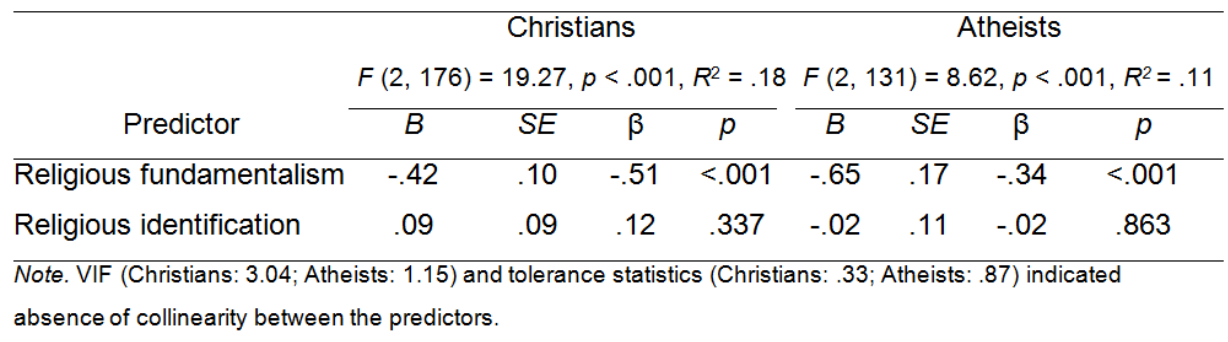


Table 2

Moderated Regression with Donation to Save the Children Syria as Dependent Variable

\begin{tabular}{|c|c|c|c|c|c|c|c|c|}
\hline \multirow[b]{3}{*}{ Predictor } & \multicolumn{4}{|c|}{ Christians } & \multicolumn{4}{|c|}{ Atheists } \\
\hline & \multicolumn{4}{|c|}{$F(5,173)=3.89, p=.002, R^{2}=.10$} & \multicolumn{4}{|c|}{$F(5,128)=2.03, p=.078$} \\
\hline & $B$ & SE & $\beta$ & $p$ & $B$ & $S E$ & $\beta$ & $p$ \\
\hline Religious fundamentalism & -1.47 & 3.10 & -.06 & .636 & -4.24 & .3 .60 & -.11 & .242 \\
\hline Religious identification & -.32 & 2.68 & -.02 & .905 & -1.86 & 2.10 & -.08 & .377 \\
\hline $\mathrm{DAC}^{1}$ & .94 & 2.29 & .03 & .683 & .48 & 1.75 & .03 & .785 \\
\hline $\mathrm{PSM}^{1}$ & .51 & .15 & 27 & .001 & .24 & .14 & .16 & .103 \\
\hline DAC X PM & .27 & .11 & .18 & .014 & .06 & .08 & .06 & 497 \\
\hline
\end{tabular}

The results supported our hypotheses. To start with, religious

fundamentalism was related to less dual Abrahamic categorization in the first regression for both groups while religious identification remained insignificant as predictor (see Table 1). However, supporting the first limiting factor, the degree to which participants perceived Syrians as a Muslim out-group moderated the relationship between dual Abrahamic categorization and donation among Christians but not among Atheists for whom Abrahamic categorization does not affect the definition of their group. Specifically, the moderated regression part of the mediational chain and, most importantly, the interaction term between dual Abrahamic categorization and percentage of Syrians perceived to be Muslim were significant only among Christians (see Table 2). Put differently, as expected, dual Abrahamic categorization was unrelated to donation among Atheists.

Also our second limiting factor obtained support. Following up on the significant moderation among Christians, analyses of the conditional effects showed that dual Abrahamic categorization lead to more donations only among participants who perceived most Syrians to be Muslim, scoring one standard deviation above the mean on the percentage variable and, hence, saw the donation as clearly supporting an Abrahamic out-group (see Figure 2). No such effect was observed for scores on the mean or one standard deviation below the mean on the percentage variable. Consistent with this finding, bias-corrected bootstrapping with 5000 bootstrap resamples confirmed that religious fundamentalism had an indirect negative effect on donation that was mediated by dual Abrahamic categorization only when participants perceived Syrians as 
predominantly being Muslim $(B=-2.70, S E=1.59,95 \%$ CI $[-6.36,-.04])$, but not when this perception was moderate $(B=-.40, S E=1.06,95 \%$ CI [-2.64, $1.65])$ or low $(B=1.90, S E=1.34,95 \%$ CI $[-.25,5.16])$.

Because our moderated mediational model was based on cross-sectional data, it was important also to test the most plausible alternative model, namely a model in which dual Abrahamic categorization is the predictor and religious fundamentalism the mediating variable. In this model, dual Abrahamic categorization predicted religious fundamentalism only weakly in the first regression $\left(\beta=-.19, S E=.05, p<.001, F(2,176)=207.37, p<.001, R^{2}=.70\right)$, while the control variable religious identification emerged as main predictor $(\beta$ $=.76, S E=.04, p<.001)$. Crucially, in the moderated regression part $(F(5,176)$ $=2.59, p=.28, R^{2}=.07$ ) the interaction term between religious fundamentalism and percentage of Syrians perceived to be Muslims $(\beta=-.07, S E=.08, p=.696)$ as well as all remaining predictors $(.118<p s<.711)$ were insignificant giving support of our hypothesized model in favor of this alternative model.

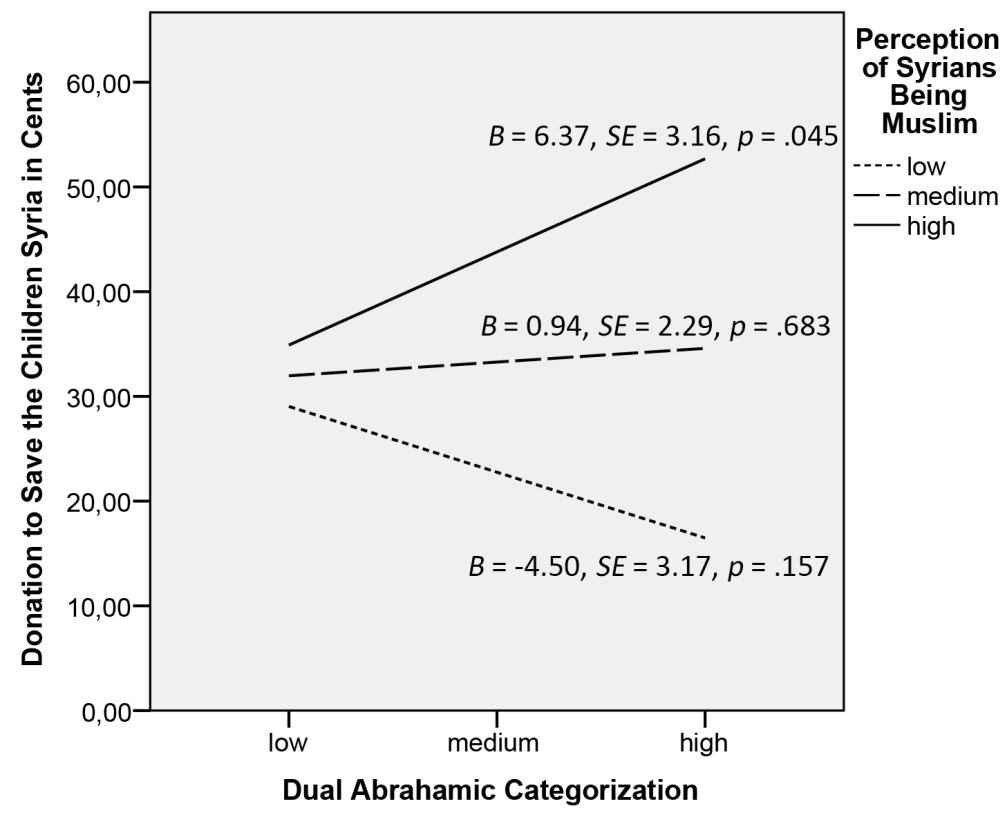

Figure 2. Simple slopes for mean donations towards Save the Children Syria regressed on interaction between dual Abrahamic categorization and perception of Syrians being Muslims in Study 1. 


\section{Study 2}

\section{Material and Methods}

Participants. Because parts of the analyses involved multi-group structural equation modelling, we aimed at recruiting between 100 and 150 participants per group as has been suggested as minimum sample size (see Wang \& Wang, 2012). In total, 288 participants from Germany (141 Christians and 147 Muslims) were recruited through advertisement on online social networks and webpages relevant to our study on "interreligious issues", satisfying this sample size criterion in both groups. The majority of participants consisted of young adults $\left(M_{\text {age }}=24.27, S D_{\text {age }}=7.41\right)$ and were male $(63.9 \%)$.

Procedure and Measures. As part of the double-randomized experimental design, participants consecutively went through a religious fundamentalism manipulation and a categorization manipulation:

Religious fundamentalism manipulation. In the first part of the experiment, we used an order-manipulation of religious fundamentalism akin to Jost and Kay (2005) to alter the salience of religious fundamentalism. This type of manipulation can be used to activate mental constructs, increasing their accessibility (Schwartz, Bless, Wänke, \& Winkielman, 2003), with subsequent effects on causally related constructs. Specifically, participants were assigned to a religious fundamentalism protrait, contrait or control group. In the protrait condition, participants indicated their agreement with five items ${ }^{3}$ from the scale used in Study 1, for which higher agreement represents more religious fundamentalism (e.g., "The fundamentals of God's religion should never be tampered with, or compromised with others' beliefs.") In the contrait condition, participants indicated their agreement with five reversed items from the same scale, for which agreement represents less religious fundamentalism (e.g., "All of the religions in the world have flaws and wrong teachings. There is no perfectly true, right religion.") In the control condition, no items were presented. Many competing theories have attempted to explain how such salience manipulations affect behavior, and uncertainty about the underlying process remains, where "one of the most critical is the question of how to predict what type of effect will emerge from any single priming event" (Loersch \& Payne, 
2011, p. 235). Indeed, it is not unusual that the same manipulations have different, sometimes opposing, effects (see Bargh, 2006 for a review). Therefore, this control group was crucial to determine whether respondents would assimilate to the items presented (e.g., by showing less endorsement of a dual Abrahamic categorization when primed with protrait fundamentalism items) or contrast to the items (e.g., by showing more endorsement of a dual Abrahamic categorization when primed with contrait religious fundamentalism items).

In each condition, participants were then asked to indicate their agreement with the dual Abrahamic categorization measure $(\alpha=.86)$ from Study 1 and to complete a Tajfel-like resource allocation task adopted from Sidanius, Haley, Molina, and Pratto (2007) ${ }^{4}$. This task tested the degree to which they maximized relative difference between the in-group and the out-group, even at the expense of absolute in-group gains. That is, was maintaining a relative bias that benefitted the in-group over the out-group so important for participants that they would even pay for it by accepting lower absolute gains? Specifically, participants had to choose one of seven alternative ways to distribute an unspecified sum of money between Christian and Islamic social organizations for the elderly. Here, a value of 1 (i.e., "190 $000 €$ for [in-group: either Christian or Muslim] organizations and $250000 €$ for [out-group: either Christian or Muslim] organizations") represents a preference for absolute in-group gain, while 4 (i.e., " $130000 €$ for [in-group] and $130000 €$ for [out-group] organizations") represents equal distribution between both groups, and a value of 7 (i.e., "70 $000 €$ for [in-group] organizations and $10000 €$ for [out-group] organizations") represents maximum in-group gain relative to the out-group. In other words, the higher individuals scored on this measure, the more they prioritized giving their group more money relative to the out-group, even when this meant that their group would receive less money in absolute terms.

Categorization manipulation. Next, individuals were once again randomly assigned to one of three categorization conditions, namely a separate groups condition, a dual Abrahamic group condition or a control condition:

- In the separate groups condition, respondents first read a text emphasizing theological differences, presented on three separate pages which 
participants had to click through to ensure that they actually read and not simply skipped the text:

"When one reads both the Bible and the Qur' an, one realizes that Islam and Christianity are two very different religions. In Christianity, Jesus is not only the son of God, but God himself. This is not the case in Islam where Jesus is just one of many prophets. In Islam, the last Prophet is Mohammed, who is not even part of Christianity. Also in terms of celebrations and traditions, Christians and Muslims are very different. While Christians celebrate the birth of Jesus, Muslims celebrate the feast of sacrifice during the Haddsch. Concluding, one can say that Islam and Christianity are very different religious groups, since Muslims and Christians believe in different things."

After reading the text, participants in this group were asked to categorize themselves as Christian, Muslim or atheist.

- In the dual Abrahamic group condition, individuals first read a text, again divided on three pages, describing theological commonalities that make both Islam and Christianity being Abrahamic religions:

"Many Christians and Muslims have forgotten the commonalities between their religions. For instance, both Islam and Christianity refer to the common progenitor Abraham and to the fact that he only believed in one god. This god, Christians and Muslims still believe in today. Also the Qur'an and Bible have many commonalities. In both books, Adam is described as the first human who had to flee from paradise. Moreover, figures such as Jesus, Moses, Noah, Ismael, Jakob, David and Jonah play important roles in both religions. Due to these various commonalities, both religions belong to the group of Abrahamic religions."

After reading the text, participants were asked to categorize themselves as Abrahamic-Christian, Abrahamic-Muslim, or atheist.

- In the control condition, participants neither read a text nor were asked to categorize themselves.

Following each experimental condition, respondents completed a second resource allocation task equal to the one described earlier, with the difference that the target groups this time constituted Christian/Muslim youth clubs. In addition, they were asked to rate their feelings towards the Abrahamic out-group (i.e., Muslims or Christians) and towards a range of non-Abrahamic groups (i.e., 
Hindus, Buddhists, Atheists and Scientologists). Here, to reduce response variations due to cultural differences between the study groups, feelings were measured on a low level of abstraction (see Mesquita \& Frijda, 1992) using a feeling thermometer adopted from Verkuyten (2007). Specifically, participants were asked to rate their feelings towards each group with " 0 " representing very cold or negative feelings and "100" representing very warm or positive feelings. Importantly, for both the resource distribution task and the feeling thermometer, in the control and separate group condition, the in- and out-groups simply were termed Muslims or Christians, whereas they were explicitly named AbrahamicMuslims and Abrahamic-Christians in the dual Abrahamic group condition to underline their fellow group membership. At the end of the study, participants answered demographical questions regarding their age, gender and religious affiliation.

\section{Results}

\section{The causal effect of manipulating the salience of religious}

fundamentalism on dual Abrahamic categorization. Testing the first causal leg of our mediational model, a 3 (religious fundamentalism saliency condition: Contrait, Protrait, Control) x 2 (religious group: Muslims, Christians) ANOVA with dual Abrahamic categorization as dependent variable and age and gender as covariates indicated a significant main effect of the saliency manipulation, $F(2$, $287)=5.88, p=.003, \eta_{\mathrm{p}}{ }^{2}=.04 ;$ a significant effect of the religious group variable with Muslims showing generally higher degrees of dual Abrahamic categorization, $F(1,287)=25.93, p<.001, \eta_{\mathrm{p}}{ }^{2}=.09$; and a significant interaction between the saliency manipulation and religious group, $F(2,287)=$ $4.45, p=.012, \eta_{\mathrm{p}}^{2}=.03$.

As predicted, the experimental manipulations of religious fundamentalism caused congruent changes in dual Abrahamic categorization. An inspection of the error bars in Figure 3 suggested that, due to a decrease in the salience of religious fundamentalism, participants in the protrait condition endorsed dual Abrahamic categorization to a greater extent $(M=4.54, S E=.14)$ than in the contrait condition $(M=3.90, S E=.14, p=.001)$ regardless of their religious denomination. However, for whatever reasons, the baseline religious fundamentalism differed between the two religious groups as indicated by the 


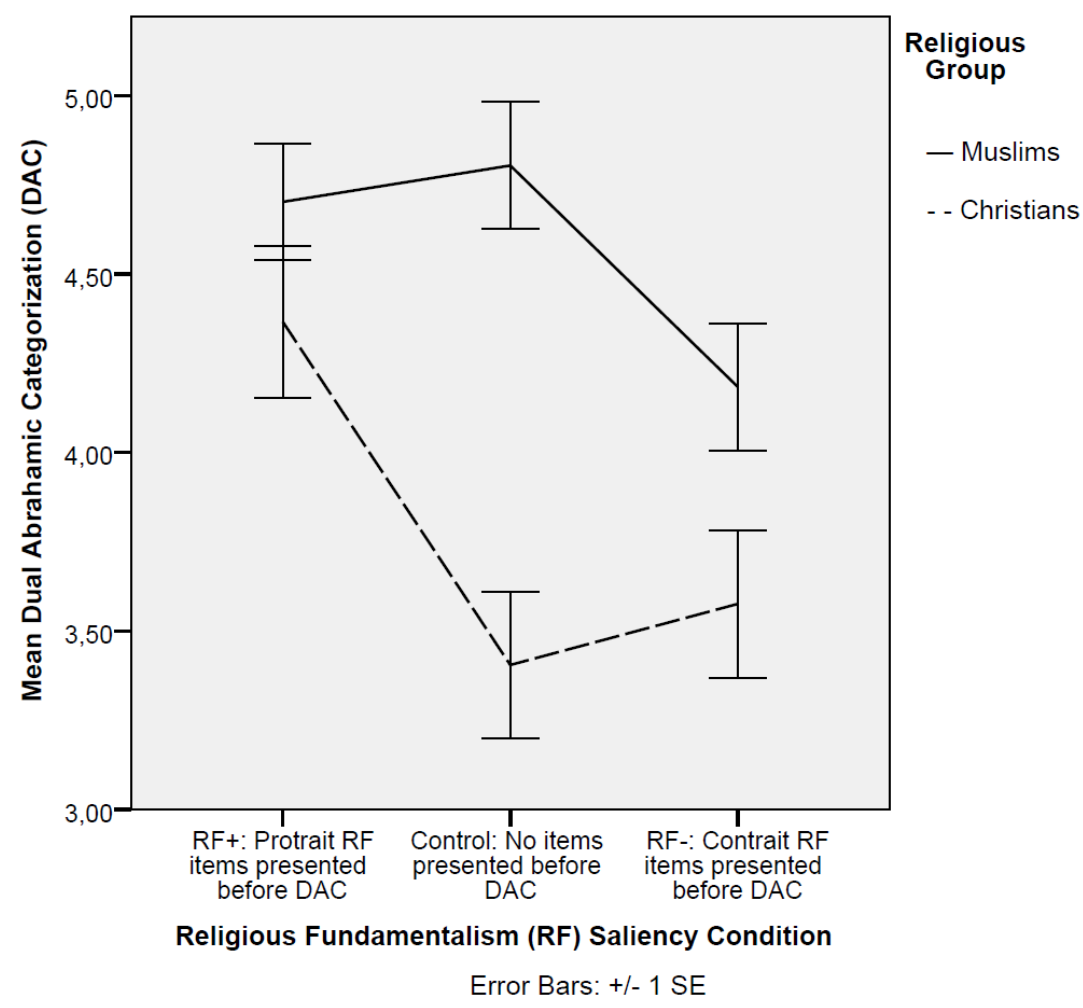

Figure 3. Effects of religious fundamentalism (RF) salience manipulation on dual Abrahamic Categorization (DAC) in Study 2 among Muslims and Christians.

agreement with dual Abrahamic categorization among participants in the control condition who had not answered to any RF items. Consequently, we constructed a new experimental dummy variable with 0 constituting anti-fundamentalism (i.e., the protrait condition) and 1 constituting pro-fundamentalism (i.e., the contrait condition) that consistently resulted in lower dual Abrahamic categorization in both groups.

As no direct effects of the experimental conditions were observed for the first distribution task $(t(185)=.34, p=.737)$, multi-group path analyses in AMOS 21 was used to test a model with the manifest experimental dummy variable as predictor, the manifest dual Abrahamic categorization variable as mediator and the manifest resource distribution task as dependent variable. A version of the model with constrained structural weights obtained a very close fit to the data, $\chi^{2}(4,187)=1.36, p=.851$, RMSEA < .001 $(90 \%$ CI $[<.001, .061]$; PCLOSE: $p=.928), \mathrm{CFI}=1.00, \mathrm{TLI}=1.15$. Importantly and further underlining the universality of the relations across the samples, no significant model-fit differences were observed between the constrained and an unconstrained version of the model, $\Delta \chi^{2}<0.00, \Delta d f=1, p=.999$. Hence, as the 
relationships tested in the model were invariant across the religious groups, the constrained model was estimated. As displayed in Figure 4, across the groups, the religious fundamentalism saliency condition negatively predicted dual Abrahamic categorization $(B=-.63, S E=.19$; Muslims: $\beta=-.22, p<.001$; Christians: $\beta=-.26, p<.001$ ) which in turn negatively related to bias in the first resource distribution task $(B=-.44, S E=.10$; Muslims: $\beta=-.33, p<.001$; Christians: $\beta=-.33, p<.001)$. Bootstrapping with 5000 bootstrap resamples showed that the resulting indirect effect was significant $(B=.52, S E=.03, \beta$ $=.09, p<.001,95 \%$ CI $[.033, .158])$.

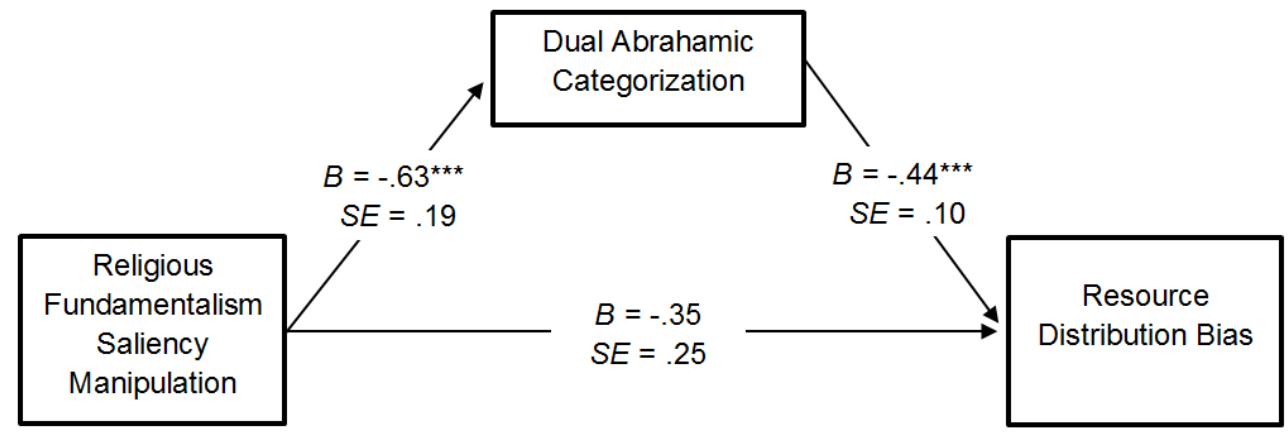

Figure 4. Estimated multi-group structural equation model among Muslims and Christians in Study 2 is displayed. Structural weights are constrained. ${ }^{* * *} p<.001$.

\section{The effect of dual Abrahamic categorization on resource distribution}

bias. Inspection of the error bars in Figure 5 showed that the separate group condition increased group bias in the second resource distribution task compared to the control group, while the dual Abrahamic categorization condition reduced bias, such that the separate and dual Abrahamic group conditions differed significantly from each other. Consequently, we conducted a 2 (experimental condition: separate group, dual Abrahamic group) x 2 (religious group: Muslims, Christians) MANOVA with all bias measures as dependent variables. We found two main effects across the bias variables:

1) Muslims generally displayed less bias towards the Abrahamic outgroup than did Christians, $F(6,175)=16.35, p<.001, \eta_{\mathrm{p}}{ }^{2}=.35$, and

2) as predicted, participants who recategorized themselves into a dual Abrahamic group showed less bias, $F(6,175)=2.37, p=.031, \eta_{\mathrm{p}}{ }^{2}=.08$. An 
insignificant interaction term between religious group and the recategorization manipulation, $F(6,175)=.81, p=.564$, demonstrated that this pattern did not differ across the two religious groups and an additional MANOVA showed that the recateogrization manipulation did no interact with the preceeding religious fundmantentalism manipulation, $F(6,109)=1.28, p=.273$.

Specifically, the between-subjects effects showed that, after recategorization into a dual Abrahamic group, participants showed less resource distribution bias on the second resource distribution taks $(M=4.01, S E=.17)$ than those in the separate group condition $(M=4.58, S E=.16 ; F(1,184)=6.11$, $\left.p=.014, \eta_{\mathrm{p}}{ }^{2}=.03\right)$. Moreover, they also showed more positive feelings towards the Abrahamic out-group $(M=64.61, S E=2.73)$ than their peers in the separate group condition $\left(M=51.88, S E=2.63 ; F(1,184)=11.26, p=.001, \eta_{\mathrm{p}}{ }^{2}=.06\right)$.

Last, again demonstrating the limiting factor that dual Abrahamic categorization only reduces bias towards Abrahamic out-groups, no other significant effects were observed for feelings towards the remaining non-Abrahamic out-groups $(.177<p s<.607)$.

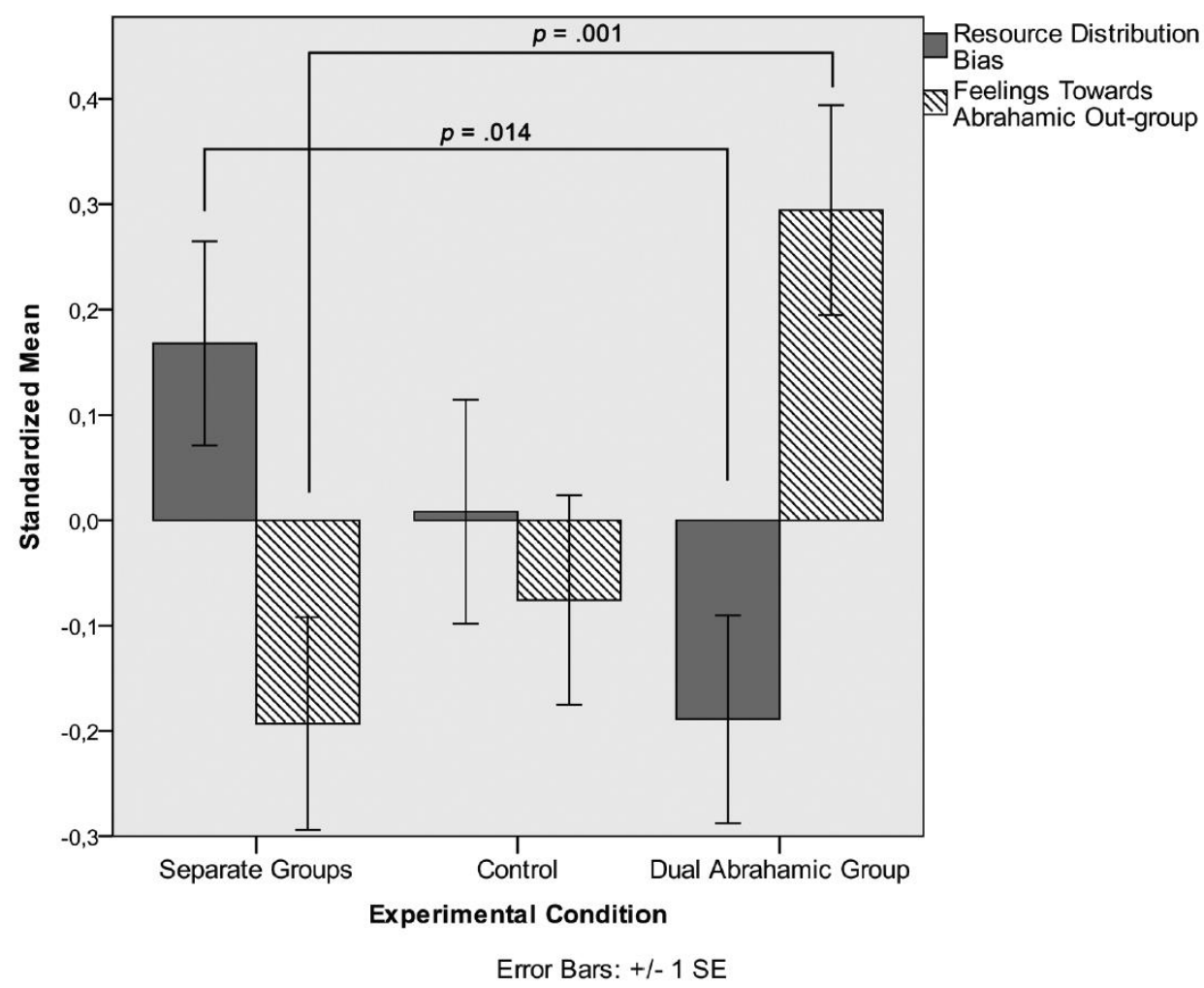

Figure 5. Difference between categorization conditions in Study 2 are displayed. Significance estimates are based on MANOVA results. 


\section{General Discussion}

Two studies, applying different methodological approaches and using samples from different cultures and cross-national and intra-national contexts, showed that religious fundamentalism leads Christian and Muslim believers alike to reject dual group categorization despite of obvious common theological grounds. This is unfortunate, because dual Abrahamic categorization, in turn and in accord with previous research on common and dual group categorizations (e.g., Dovidio et al., 2007; Dovidio, Saguy, \& Shnabel, 2009), consistently led to less bias towards the Abrahamic out-group in terms of real monetary donations to out-group children desperately in need, resource distribution scenarios and intergroup feelings.

Yet, although dual Abrahamic categorization emerges here as a promising construct for Christian-Muslim relations, two caveats have to be mentioned: First and as predicted, dual Abrahamic categorization had no effect on group bias among Atheists for whom dual Abrahamic categorization should be irrelevant for their self-concepts and simply represent knowledge about Abrahamic groups. Second, although dual categorization led to less group bias among believers as predicted, it did so only when the out-group was seen as part of the relevant Abrahamic group. Hence, dual Abrahamic categorization seems to leave general religious tolerance unaffected.

While religious fundamentalism has been associated with conflicts between religious groups in many parts of the world (Emerson \& Hartman, 2006), little has been known about the underlying psychological mechanisms of this relationship. The present paper suggests that one central reason for why religious fundamentalism is particularly destructive for inter-religious relations is that it literally divides religious groups, making believers think less in terms of theological commonalities and more in terms of theological differences, reinforcing social psychological divisions a lá "us vs them". 
References

Altemeyer, B. (2003). Why do religious fundamentalists tend to be prejudiced? International Journal for the Psychology of Religion, 13(1), 17-28. doi:

10.1207/S15327582IJPR1301_03

Altemeyer, B., \& Hunsberger, B. (1992). Authoritarianism, religious fundamentalism, quest, and prejudice. International Journal for the Psychology of Religion, 2(2), 113-133. doi: $10.1207 / \mathrm{s} 15327582 \mathrm{ijpr} 0202 \_5$

Altemeyer, B., \& Hunsberger, B. (2004). A revised religious fundamentalism scale: The short and sweet of it. International Journal for the Psychology of Religion, 14(1), 47-54. doi: 10.1207/s15327582ijpr1401_4

Bargh, J. A. (2006). What have we been priming all these years? On the development, mechanisms, and ecology of nonconscious social behavior. European Journal of Social Psychology, 36(2), 147-168. doi: 10.1002/ejsp.336

Brandt, M. J., \& Reyna, C. (2010). The role of prejudice and the need for closure in religious fundamentalism. Personality and Social Psychology Bulletin, 36(5), 715-725. doi: $10.1177 / 0146167210366306$

Dovidio, J. F., Gaertner, S. L., \& Saguy, T. (2007). Another view of "we": Majority and minority group perspectives on a common ingroup identity. European Review of Social Psychology, 18(1), 296-330. doi: 10.1080/10463280701726132

Dovidio, J. F., Gaertner, S. L., Shnabel, N., Saguy, T., \& Johnson, J. (2009). Recategorization and prosocial behavior: Common in-group identity and a dual identity. In S. Stürmer \& M. Snyder (Eds.), The Psychology of Prosocial Behavior (pp. 191-207). WestSussex, United Kingdom: Wiley-Blackwell.

Dovidio, J. F., Saguy, T., \& Shnabel, N. (2009). Cooperation and conflict within groups: Bridging intragroup and intergroup processes. Journal of Social Issues, 65(2), 429-449. doi: $10.1111 / \mathrm{j} .1540-4560.2009 .01607 . \mathrm{x}$

Edwards, J. R., \& Lambert, L. S. (2007). Methods for integrating moderation and mediation: A general analytical framework using moderated path analysis. 12, 1-22. doi: 10.1037/1082-989X.12.1.1

Emerson, M. O., \& Hartman, D. (2006). The rise of religious fundamentalism. Annual Review of Sociology, 32, 127-144. doi: 10.2307/29737734

Gaertner, S. L., \& Dovidio, J. F. (2000). Reducing intergroup bias: The Common Ingroup Identity Model. Philadelphia, US-PA: Psychology Press.

Gaertner, S. L., \& Dovidio, J. F. (2005). Understanding and addressing contemporary racism: From aversive racism to the common ingroup identity model. Journal of Social Issues, 61(3), 615-639. doi: 10.1111/j.1540-4560.2005.00424.x

Hall, D. L., Matz, D. C., \& Wood, W. (2010). Why don't we practice what we preach? A meta-analytic review of religious racism. Personality and Social Psychology Review, 14(1), 126-139. doi: 10.1177/1088868309352179

Hayes, A. F. (2013). Introduction to mediation, moderation, and conditional process analysis: A regression-based approach. New York, US-NY: Guilford Press.

Hunsberger, B., \& Jackson, L. M. (2005). Religion, meaning, and prejudice. Journal of Social Issues, 61(4), 807-826. doi: 10.1111/j.1540-4560.2005.00433.x

Jost, J. T., \& Kay, A. C. (2005). Exposure to benevolent sexism and complementary gender stereotypes: consequences for specific and diffuse forms of system justification. Journal of Personality and Social Psychology, 88(3), 498-509. doi: 10.1037/00223514.88.3.498

King Hussein I. (1991). Address to the European Parliament. 
Loersch, C., \& Payne, B. K. (2011). The situated inference model: An integrative account of the effects of primes on perception, behavior, and motivation. Perspectives on Psychological Science, 6(3), 234-252. doi: 10.1177/1745691611406921

Luhtanen, R., \& Crocker, J. (1992). A collective self-esteem scale: Self-evaluation of one's social identity. Personality and Social Psychology Bulletin, 18(3), 302-318. doi: 10.1177/0146167292183006

MacKinnon, D. P., Fairchild, A. J., \& Fritz, M. S. (2007). Mediation analysis. Annual Review of Psychology, 58(593), 1-22. doi: 10.1146/annurev.psych.58.110405.085542

Mesquita, B., \& Frijda, N. H. (1992). Cultural variations in emotions: A review. Psychological Bulletin, 112(2), 179-204. doi: 10.1037/0033-2909.112.2.179

Plante, T. G. (2009). A commentary on religious conflicts and a call for a focus on the best the traditions have to offer. Pastoral Psychology, 58(1), 73-78. doi: 10.1007/s11089008-0172-8

Schwartz, N., Bless, H., Wänke, M., \& Winkielman, P. (2003). Accessibility revisited. In G. V. Bodenhausen \& A. J. Lambert (Eds.), Foundations of social cognition:

A festschrift in honor of Robert S. Wyer, Jr. (pp. 51-78). Mahwah, US-NJ: Lawrence Erlbaum. Sherman, S. J., \& Gorkin, L. (1980). Attitude bolstering when behavior is inconsistent with central attitudes. Journal of Experimental Social Psychology, 16(4), 388-403. doi: 10.1016/0022-1031(80)90030-x

Sidanius, J., Haley, H., Molina, L., \& Pratto, F. (2007). Vladimir's choice and the distribution of social resources: A group dominance perspective. Group Processes \& Intergroup Relations, 10(2), 257-265. doi: 10.1177/1368430207074732

Tajfel, H. (1982). Social identity and intergroup relations. Cambridge, England: Cambridge University Press

Tajfel, H., \& Turner, J. C. (1979). An integrative theory of intergroup conflict. . In W. G. Austin \& S. Worchel (Eds.), The social psychology of intergroup relations (pp. 33-47). Monterey, US-CA: Brooks/Cole.

Tanaka, J. S. (1987). "How big is big enough?": Sample size and goodness of fit in structural equation models with latent variables. Child Development, 58(1), 134-146. doi: $10.2307 / 1130296$

Verkuyten, M. (2007). Religious group identification and inter-religious relations: A study among Turkish-Dutch Muslims. Group Processes \& Intergroup Relations, 10(3), 341357. doi: $10.1177 / 1368430207078695$

Wang, J., \& Wang, X. (2012). Structural equation modeling: Applications using Mplus. New York, US-NY: John Wiley \& Sons. 


\section{Footnotes}

${ }^{1}$ http://www.savethechildren.org/site/c.8rKLIXMGIpI4E/b.7998857/k.D075/Syria.htm

${ }^{2} \mathrm{An}$ emotion measure that also was part of the original survey is not presented here due to reasons of brevity and the behavioral focus of the study.

${ }^{3}$ Two items of the religious fundamentalism scale that dealt with theologically variant constructs such as Satan were excluded.

${ }^{4}$ Participants also responded to a stereotypes and emotions measure which we, however, chose not to elaborate on because we were primarily interested in behavioral aspects of intergroup bias. 